\title{
Evaluating the impact of road construction on landslide susceptibility- A case study of Mandi district, Himachal Pradesh, India.
}

\author{
Amol Sharma ${ }^{1}$ and Chander Prakash ${ }^{1}$ \\ ${ }^{1}$ NIT Hamirpur
}

May 18, 2021

\begin{abstract}
Landslide susceptibility mapping has proved to be crucial tool for effective disaster management and planning strategies in mountainous regions. The present study is perused to investigate the changes in the landslide susceptibility of the Mandi district of Himachal Pradesh due to road construction. For this purpose, an inventory of 1723 landslides was generated from various sources. Out of these, 1199 (70\%) landslides were taken in the training dataset to be used for modelling and prediction purposes, while $524(30 \%)$ landslides were taken in the testing dataset to be used for validation purposes. Eleven landslide causative factors were selected from numerous hydrological, geological and topographical factors and were analyzed for landslide susceptibility mapping using three bivariate statistical models, namely; Frequency Ratio (FR), Certainty Factor (CF) and Shanon Entropy (SE). Two sets of LSM maps i.e. landslide susceptibility map natural (LSMN) and landslide susceptibility map road (LSMR), were generated using the above mentioned bivariate models and were divided into five landslide susceptibility classes namely; very low, low, medium, high and very high. These maps were analyzed for accuracy of prediction and validation using receiver operating characteristic (ROC) curves and area under curve (AUC) technique which indicated that all three bivariate statistical models performed satisfactorily with the SE model had the highest prediction and validation accuracy of 83-86\%. Further analysis LSM maps confirmed that the percentage area in high and very high classes of land-slide susceptibility increased by $2.67-4.17 \%$ due to road construction activities in the study area.
\end{abstract}

\section{Evaluating the impact of road construction on landslide susceptibility- A case study of Mandi district, Himachal Pradesh, India.}

Amol Sharma ${ }^{\mathrm{a} *}$, Chander Prakash ${ }^{\mathrm{b}}$

a,b Department of Civil Engineering, National Institute of Technology, Hamirpur, India

\begin{abstract}
Landslide susceptibility is crucial for effective hazard management, planning mitigation and risk reduction strategies. In the present study, impact of road construction on landslide susceptibility is assessed for Mandi district. 1723 landslides data for Mandi district was compiled from the various sources with eleven causative factors. The eleven landslide causative factors were selected from numerous hydrological, geological and topographical factors. The landslide susceptibility analysis was carried out using three bivariate statistical models, namely, Frequency Ratio (FR), Certainty Factor (CF) and Shanon Entropy (SE). Two sets of Landslide Susceptibility Maps were generated for assessing the impact of road construction and were divided into five landslide susceptibility classes. The SE model had the highest prediction and validation accuracy
\end{abstract}


of $(83-86 \%)$. The percentage area in high and very high classes of landslide susceptibility increased by 2.67$4.17 \%$ due to road construction activities in the study area.

Keywords: Landslide; Bivariate Models; ROC; Multicollinearity; Remote Sensing

*Corresponding Author Email: amol@nith.ac.in

\section{Introduction}

The adverse impacts of landslides on the socio-economic environment are increasing rapidly on a local and global scale. Due to complex physiography and increasing anthropological activities, Himachal Pradesh is recognised for frequent landslide occurrences, especially during the monsoon season. Rainfall induced landslide of Kotrupi on 13 August 2017 was one such devastating incidence. At least 46 people lost their lives as two state transportation busses got buried under a massive landslide along National Highway- 154 . The highway construction in mountainous regions significantly influences landslide occurrences (Dugonji, 2014). As many highways are under construction and many are in the planning phase in Himachal Pradesh which continuously interfere and destabilise the natural bed slope. The deforestation along the highway alignment also enhances the risk of landslides in Himachal Pradesh.

To quantify and manage the risk due to landslides, the landslide susceptibility analysis and mapping is of utmost importance. Landslide susceptibility of a region can be described as the probability with which a landslide can occur in a region based on that region's topographical and geographical conditions (Brabb, 1984) and the previous occurrences of landslides in the region (Nohani et al., 2019). Generally, landslide susceptibility is shown on maps that display multi-layered spatial and temporal distribution and the probability with which landslides can occur (Nagarajan et al., 1998). The susceptibility analysis and zonation of landslide hazard is considered as a complex process. It is a readily perceived research area in recent times, and experts have proposed various techniques and methodologies in different geological and meteorological settings (Nayak, 2010; Reichenbach et al., 2018). The multiple stages of landslide risk analysis and management, as compiled by (Fell, 1993), are widely accepted in evaluating and analysing landslide hazard. Various studies have shown the suitability of remote sensing and geomatics-based approaches for susceptibility analysis on a regional scale due to availability of spatially and spectrally varied temporal data (Prakash and Nagarajan., 2018). The remote sensing and GIS-based approaches using high/medium-resolution satellite imagery and Digital Elevation model allows a cost effective and rapid extraction of geological and topographical data on the regional scale (Prakash and Nagarajan., 2017). The first stage in most of the landslide susceptibility mapping methods is to develop a comprehensive landslides inventory map by compiling landslide event data from the various sources for the region. (Pradhan et al., 2014). Landslide hazard assessment and susceptibility analysis are highly dependent on the accuracy of landslides data acquisition and mapping (Henriques et al., 2009; Guzzetti, 2005). Landslide inventory map can be prepared from satellite image by visual interpretation and computer processing of the imagery, field inspections, aerial photographs, high resolution DEM and available data from various published reports (Remondo et al., 2003).

The next phase in landslide susceptibility analysis is to formulate layers of thematic variables of landslide causative factors leading to slope instability. The factors affecting land surface include regional geology, slope curvature, aspect, soil, distance to road, elevation, lineament density, drainage network, NDVI etc. These factors can be extracted and mapped using high resolution remote sensing images, arial photographs, published maps and digital elevation models (DEM) using geospatial tools and techniques. Remote sensing data has been accepted as the most accurate and authentic source of Earth's surface data (Banshtu and Prakash, 2014). Remote sensing provides the benefit of mapping landside areas according to research demand using updated satellite images (Jaiswal, 2009). These satellite images and aerial photographs being stereoscopic provides three dimensional perspectives for the characterisation of landslides based on their spatial and temporal features of the region (Mantovani et al., 1996; Chakraborthy, 2008). This spatial and temporal thematic dataset needs to be integrated with ground based information (Nagarajan et al., 1998). 
For this purpose, GIS is a widely accepted tool to store extensive data (Rengers et al., 1992; Soeters et al., 1991). GIS can manipulate and analyse remotely sensed data for assessing landslide hazard (Carrara et al., 1991; McKean et al., 1991). The factors can then be ranked according to available codes, expert opinions, statistical modelling and multicriteria evaluation based techniques (Reichenbach et al., 2018). Hence using GIS in analysing remotely sensed images and DEM's can be considered as a highly efficient tool for landslide susceptibility mapping (Van Westen, 2000; Jebur et al., 2014b).

Geo-physical laws generally control landslides occurrence, and statistical, empirical and deterministic methods can be used for their analysis (Crozier, 1989; Hutchinson, 1988; Dietrich et al., 1995). The key to predicting landslides of the future is to analyse the past and present scenarios (Varnes, 1984). Along with this, various quantitative and qualitative approaches have been developed, helping determine the frequency and probability of a landslide event (Frangov et al., 2017). Some of the most accurate statistical techniques in landslide susceptibility modelling include logistic regression analysis, data overlay analysis, multi criteria analysis, the weight of overlay analysis, bivariate analysis and entropy based analysis etc. (Huabin et al., 2005; Kanungo et al., 2009; Reichenbach et al., 2018).

The present study is perceived with the motivation that road construction activities significantly influence the study area's landslide susceptibility. Despite ever increasing landslide incidences along the highways, there is still a significant research gap in comprehensive studies regarding road construction's impact on landslide susceptibility of a mountainous region like the Mandi District of Himachal Pradesh. Hence this study aims to compare the change in Landslide Susceptibility of Mandi district due to construction of roads in the district using Frequency Ratio (FR), Certainty Factor (CF) and Shanon Entropy (SE) models.

\section{Study Area}

Mandi district is located at the central region of Himachal Pradesh between $31^{\circ} 13^{\prime}$ and $32^{\circ} 05^{\prime}$ North latitudes and $76^{\circ} 37^{\prime}$ and $77^{\circ} 25^{\prime}$ East longitudes. The district is the second most populated district of Himachal Pradesh, with a total area of $3,951 \mathrm{~km}^{2}$ and a population density of 250 persons $/ \mathrm{km}^{2}$ having a road density of 155 $\mathrm{km}$ per $100 \mathrm{~km}^{2}$. Two major National Highways that run across the district's length and breadth are NH-3 (Atari-Manali-Leh) and NH-154 (Pathankot-Sundernagar-Bilaspur). The climate of the region is sub-tropical in the valleys but tends to be temperate near the hilltops. The annual average rainfall in the district is 255 $\mathrm{mm}$ with average monthly rainfall extremities ranging from $10 \mathrm{~mm}$ in November to $345 \mathrm{~mm}$ in July. The elevation increase from west to east and south to north with altitude of the area ranging from $500 \mathrm{~m}$ to $3400 \mathrm{~m}$. The soils of Lesser Himalayas and Siwaliks are mainly found in the district, which is generally high in organic matter and characterised by rugged topography. Hydro-geologically, the district has two distinct and well defined units, viz. porous formations constituted by unconsolidated sediments and the fissured formations. Forests, sparse and dense vegetation cover the majority of the district area. The Beas river runs through the northern part of the district whereas the southern part is drained by the Satluj river as shown in Figure 1.

\section{Materials and Methods}

\subsection{Data Sources}

The Operational Land Imager (OLI) and Thermal Infrared Sensor (TRIS) of Landsat-8 satellite having 12Band multispectral images of the 30-m resolution were downloaded from United States Geological Survey (USGS) Earth Explorer website. The multispectral images from the year 2015 to 2020 from the first week of October to the last week of November, just after the monsoon season is over as maximum landslides incidences in the Mandi district occurred during the monsoon season, were considered adequate due to the availability of cloud-free data. These high resolution multispectral images were already terrain corrected 
and were suitable for analysing the study area's terrain characteristics. Advanced Land Observing SatellitePhased Array Type L-band Synthetic Aperture Radar (ALOS-PALSAR) Digital Elevation Model (DEM) of $12.5 \mathrm{~m}$ resolution was downloaded from the Alaska Satellite Facility website. This DEM was used to derive topographical information such as slope, curvature, aspect and drainage density etc., of the study area. A geological map of the study area was obtained from India's Geological Survey (GSI) Bhukosh portal. The Mandi district's soil map was generated using published Soil Map of Himachal Pradesh procured from the Indian Council of Agricultural Research-National Bureau of Soil Survey and Land Use Planning (ICARNBSS-LUP). The road network for the study area was developed from the published maps from the portal of Ministry of Road Transport and Highways (MoRTH). Table 1. Depicts various data sources used and their purpose in the present study.

\subsection{Landslide Inventory Dataset}

In the present study, landslide occurrences in the study area were detected and mapped using three sources (a) landslide data from Himachal Pradesh government disaster revenue reports and various documented sources such as Bhukosh portal of GSI (b) High resolution Google Earth images were used as an auxiliary data source and are analysed through visual interpretation to identify landslides and (c) through extensive field surveys using handheld GPS. The analysis of factors responsible for triggering landslides is necessary as it gives a relationship between various conditions that might be responsible for disrupting the stable slope conditions. (Crozier and Glade, 2003). The various triggering factors in study area are earthquakes, soil erosion, deforestation, mining infrastructure development etc. It was found that the most common triggering factor for all the landslides in the region was rainfall. Hence all landslides are treated as rainfall induced landslides in the present study. A total of 1723 landslides and their location, type and other required information were documented for developing a GIS based landslide inventory of the district. The landslide inventory was subdivided into a training set of 1199 landslides (70\%) for landslide susceptibility analysis and a validation set of 524 landslides (30\%) using random sampling in ArcGIS as shown in Figure 2.

\subsection{Landslide Causative Factors}

The interaction between geological, morphometric, topographical and hydrological factors in a region influences landslides' occurrence. Hence the appropriate selection of these causative factors is a primary step in landslide susceptibility analysis ( Lee et al., 2004; Dou et al., 2015). In the present study, based upon the previous studies and expert opinions, eleven landslide causative factors namely slope gradient, plan curvature, aspect, elevation, drainage density, lineament density, geology, NDVI, soil, TWI and distance from the road were selected for the analysis. As there were variable scales of various causative factors, therefore all these were resampled into a raster format of $30 \mathrm{~m}$ resolution to commensurate the diversity for geoprocessing and map algebra analysis through ArcGIS.

The slope gradient is considered a significant factor that influences landslides in a particular area as it quantifies the amount of shear force acting on a specific area of sliding. (Saha et al., 2005; Pradhan and Lee, 2010). The slope gradient map prepared from the $12.5 \mathrm{~m}$ ALOS PALSAR DEM of the Mandi district is shown in Figure-3. The study area exhibits a considerable variation in slope gradients with slopes ranging from $0^{\circ}$ to $82^{\circ}$ which gives rise to flatter terrains along the valleys to extremely steep terrains along the mountains. The relief features of the region are extensively used in landslide susceptibility analysis as it affects rainfall, seismicity, etc. (Pham, 2017). The north eastern part of the Mandi district is dominated by a higher elevation which ranges from 3000 to $6000 \mathrm{~m}$. The northern part of the Mandi district is surrounded by Beas river which is characterised by a lower elevation, including Balh Valley. The slope aspect of the area tends to be relatively evenly distributed in all directions, although southward directions have slight predominance. The plan curvature of the area is predominantly flat to slightly concave. The Plan Curvature of slope represents the direction of maximum slope and helps identify the morphology of the area's topography (Erener and Düzgün, 2012; Pourghasemi et al., 2012). The drainage density, the measure of the density of streams and rivers in a drainage basin, directly influences slope's erodibility dissected by channels and influences the 
surface runoff (Demir et al., 2014). The drainage density of the Mandi district ranges from $0-2.4$ and is subdivided into five classes. Hydrological impact of drainage networks on the wetness/saturation of the soils on the slopes is assessed and quantified using Topographic Wetness Index (TWI) (Beven and Kirkby, 1979). The TWI map of study area was prepared by combined arithmetic application of morphometric variables, including the slope gradient and flow accumulation parameters, using Equation (1) with values ranging from 4.0 - 28.0. Normalised Difference Vegetation Index (NDVI) map is one of the most fundamental and widely accepted index to detect vegetation and landcover changes caused by infrastructural developmental activities. (Carrara et al., 1982; Ceballos and Lopez, 2003; Ahmad et al., 2013). Normalised Difference Vegetation Index (NDVI) map was prepared using image analysis techniques on high resolution Landsat-8 images of the study area using ERDAS IMAGINE software using Equation (2). The primary NDVI zone of the study area was shrubs and grasslands (45\%), followed by sparsely vegetated (28\%) and urban area (12\%). Lineaments are the linear weaknesses or fracture planes such as cracks, faults, bleeding planes, joints etc. which represents the underlying geology of the area (Ramakrishnan et al., 2013). It was found that almost $35 \%$ of the total area had high to very high lineament density, and $26 \%$ of the total area had a moderate density of lineaments. Geological boundaries of an area are closely related to slope and rock strength, and such boundaries may lead to increased landslide activity. Mandi district lies within the lesser Himalayan and Siwalik region and was classified into five zones based on their slopes and terrain characteristics (Choubey et al., 2007; Dou, 2014). Different types of soils have different cohesion values, and the infiltrated water might be able to erode the soils with lesser cohesion values. (Mzuku et al., 2005; Godt et al., 2009; Baum, 2010). The Mandi district's soil map was classified into five categories of soils based on their depth, drainage, and erosion properties. The construction of roads in mountainous terrain often includes excavation along the natural bed slope. This usually results in loss of support and cracks development due to increased strain in the upper soil mass. (Devkota et al., 2013; Pradhan et al., 2018) As a result, landslides occurrences are mostly distributed near the road network. (Ayalew and Yamagishi, 2005; Tuan and Dan, 2012). The road network distribution was reclassified into five road buffer zones from 0-500 $\mathrm{m}$ at $100 \mathrm{~m}$ intervals.

$\mathrm{TWI}=[\operatorname{Ln}(\mathrm{As}) / \operatorname{Tan}(\beta)](1)$

Where $\mathrm{Ln}$ is natural $\log , \mathrm{A}_{\mathrm{s}}=$ Flow Accumulation, $\beta=$ Slope in Radians

$\mathrm{NDVI}=(\mathrm{NIR}-\mathrm{RED}) /(\mathrm{NIR}+\mathrm{RED})(2)$

NIR (Near Infra-Red Band) and RED Band represent the electromagnetic spectrum's spectral reflectance bands.

\subsection{Statistical Landslide Susceptibility Models}

Statistical bivariate models are widely accepted methods of quantitative analysis of landslide data. They generate a statistical relationship between the dependent variable (known landslides distribution) with a set of independent variables (landslide causative factors) to predict landslide susceptibility of an area. (Carrara et al., 1991; Chung et al., 1995; Guzzetti et al., 2006b; Rossi et al., 2010). In this study, landslide susceptibility analysis was carried out using three statistical models, i.e. Frequency Ratio (FR), Certainty Factor (CF) and Shanon Entropy. The data of all landslide causative factors were resampled into raster format of spatial resolution of $30 \mathrm{~m}$. The accuracy of these models was validated by plotting the Receiver Operating Characteristics Curve (ROC) using Monte Carlo Simulation in the SDM tool in ArcGIS. The detailed methodology used in the present study is described using a flowchart as shown in Figure 4.

\subsubsection{Frequency Ratio Model}

Frequency ratio (FR) is an observation based statistical model representing the probability of occurrence of landslides for a given influencing parameter by correlating them with the existing distribution of landslides (Lee and Pradhan, 2007; Bonham and Carter, 2014). FR model associates the pixel data with and without landslides with pixels of input raster data layers of causative factors. The FR value is then computed for each class of particular causative factor using Equation (3). FR values greater than 1 indicate a higher 
proportion of landslide occurrence and a high correlation with that specific class of causative factor. On the contrary, FR value less than 1 indicates a lower correlation with that particular causative factor. (Akgun, 2008; Karim et al., 2011)

$F R(i)=\frac{N p i x(l i) / N p i x(c i)}{\sum N p i x(l i) / \sum N p i x(c i)}(3)$

Npix $($ li) $=$ Number of pixels containing landslides in each class (i) of the causative factor

Npix $($ ci) $=$ Total number of pixels in each class (i) of the causative factor

$[?] \operatorname{Npix}($ li $)=$ Total number of pixels containing landslides in the study area

[?] $\operatorname{Npix}($ li $)=$ Total number of pixels in the whole study area

To prepare final LSM maps, the FR values of all the landslide causative classes have to be integrated using Equation (4)

$\mathrm{LSM}_{\mathrm{FR}}=\mathrm{FR}_{1}+\mathrm{FR}_{2}+\mathrm{FR}_{3}+\ldots+\mathrm{FR}_{\mathrm{n}}(4)$

\subsubsection{Certainty Factor Model}

The Certainty Factor ( $\mathrm{CF}$ ) model is one of the most fundamental and widely accepted model for landslide susceptibility mapping. (Kanungo et al., 2011; Liu et al., 2014). It provides a rule based favourability function to consolidate heterogeneous data layers using Equation (5).

$\mathrm{CF}=$

$\frac{\mathrm{ppa}-\mathrm{pps}}{\mathrm{ppa}(1-\mathrm{pps})} \quad a m p ;$ when ppa $\geq \mathrm{pps}$

$\frac{\mathrm{ppa}(1-\mathrm{pps})}{\mathrm{pps}(1-\mathrm{pp})} \quad a m p ;$ when ppa $<\mathrm{pps}$

Where CF is the Certainty Factor, ppa is the conditional probability of having a landslide event occurring in class "a", and pps is the prior probability of having the total number of landslides in the study area "A".

The $\mathrm{CF}$ value ranges between -1 and +1 , where +1 is the measure of belief (definitely true) or increasing certainty of landslide occurrence and -1 is the measure of disbelief (definitely false) or decreasing certainty of landslide occurrence. CF value nearby 0 indicates that the conditional probability is very close to the prior probability, and hence it is difficult to ascertain any certainty of landslide occurrence (Lee and Talib, 2005; Pourghasemi et al., 2012e). The pairwise data layers of all landslide causative factors were combined based on "Z" values obtained from Equation (6) (Dou et al. 2014; Ilia et al. 2015).

$$
\begin{array}{cc}
A+B-A B & a m p ; A, B \geq 0 \\
Z=(A+B) /(1-\min (|A|,|B|)) & \text { amp } ; A * B<0(6) \\
A+B+A B & a m p ; A, B<0
\end{array}
$$

These pairwise combinations have to be persistently performed on all causative factors using the integration rule until all data layers were combined to prepare final LSM maps.

\subsubsection{Shanon Entropy Method}

The entropy of a system conceptually measures the degree of randomness, disorder, uncertainty or instability. Thermodynamically as Boltzmann described, entropy is used to represent the direction of the spontaneity of a process. Claude Shannon in 1948 developed the concept of entropy to analyse a fundamental communication problem of information theory. The Shanon Entropy (SE) model can be used to measure the uncertainty in the information of various landslide causative parameters (Bednarik, 2010; Pourghasemi, 2012; Nohani et al., 2019). The probability density $P_{\mathrm{ij}}$ values for each class is calculated using Equation (7), which are further used to calculate the information coefficients $H_{j}$ using Equation (8).

$P_{\mathrm{ij}}=\frac{\mathrm{FR}}{\sum_{j=1}^{N_{j}} \mathrm{FR}}(7)$ 
where $P_{\mathrm{ij}}$ represents the probability density of each sub class, and FR represents the frequency ratio of each class.

$$
E_{j}=-\sum_{i=1}^{N_{j}} P_{\mathrm{ij}} P_{\mathrm{ij}}, j=1, \ldots, n
$$

$E_{\text {jmax }}=N_{j}, j=$ number of sub classes

$H_{j}=\left(E_{\text {jmax }}-E_{j} / E_{\text {jmax }}\right), H=(0,1), j=1, \ldots, \mathrm{n}$

$W_{j}=H_{j} * F R(8)$

Where $E_{j}$ and $E_{\text {jmax }}$ are the entropy values, $H_{j}$ is the information coefficient, $N_{j}$ is the number of classes in each landslide causative factor. $W_{j}$ calculated from Equation (8) is the relative weight assigned to each landslide causative factor on the whole. $W_{j}$ values closer to 1 represent higher uncertainty or inconsistency, whereas values closer to 0 represents higher certainty or consistency. The final LSM maps were prepared by using Equation (10)

$\mathrm{LSM}_{\mathrm{SE}}=W_{1} * \mathrm{FR}_{1}+\mathrm{W}_{2} * \mathrm{FR}_{2}+\mathrm{W}_{3} * \mathrm{FR}_{3}+\ldots+\mathrm{W}_{n} * \mathrm{FR}_{\mathrm{n}}(9)$

\section{Results}

\subsection{Multicollinearity Analysis}

Multicollinearity analysis is a statistical concept and is generally carried out to check for correlation between various independent variables (Nohani et al., 2019; Roy et al., 2019). In this study, a multicollinearity test was conducted to analyse the correlation between 11 independent landslide causative factors using IBM SPSS Statistics software. The Variance Inflation Factor (VIF) and tolerance values obtained from the multicollinearity analysis are shown in Table 2 . The VIF values $>10$ or tolerance values $<0.1$ suggest the problem of collinearity among the independent variables. It can be seen from Table 2 . that there is no issue of collinearity among independent variables as all values of tolerance and VIF were found satisfactory. Hence all selected landslide causative factors were found suitable for landslide susceptibility analysis.

\subsection{Relationship between Landslide Causative Factors and Landslide Occurrence}

LSM maps of the study area were prepared using three bivariate statistical models and were further analysed for landslide susceptibility change due to road construction. This was done by preparing two types of LSM maps. The first map, termed as Landslide Susceptibility Map Natural $\left(\mathrm{LSM}_{\mathrm{N}}\right)$, was formulated, taking into account only ten landslide causative factors excluding distance from road factor. Similarly, the second map, termed as Landslide Susceptibility Map Road $\left(\mathrm{LSM}_{\mathrm{R}}\right)$, was prepared, taking into account all the eleven landslide causative factors, including distance from the road factor, using Equation (4). The $\mathrm{LSM}_{\mathrm{N}}$ and $\mathrm{LSM}_{\mathrm{R}}$ maps were classified into five landslide susceptibility zones: very low, low, moderate, high, and very high susceptibility, as shown in Figure 5.

The FR values of each class of eleven landslide causative factors based on their correlation with the landslide occurrences are shown in Table 3. The $\mathrm{LSM}_{\mathrm{N}}$ and $\mathrm{LSM}_{\mathrm{R}}$ maps analysis indicates that drainage density, TWI, NDVI and distance from road (for $\mathrm{LSM}_{\mathrm{R}}$ only) were the critical factors that affect the study area's landslide susceptibility. While analysing the hydrological parameters, the highest FR values were obtained for areas with very high drainage density (14.7) and very high TWI (49.7). Such areas were found to be more susceptible to landslides. Also, it was found that areas near the vicinity of roads are generally more prone to landslides. Further, the FR values of the distance from the road classes of 0-100 m (6.4) and 100-200 m (5.7) were found to be highest therefore, such areas were found to be more landslide prone. The study area was categorised into five NDVI classes: waterbodies, urban area, barren land, shrubs and grasslands, and 
sparse and dense vegetation. The areas closer to waterbodies had the highest FR value (7.7), followed by urban areas where human interference with natural slopes was observed.

The analysis of CF values indicated a similar trend with classes of very high drainage density (0.93), very high TWI (0.98), NDVI waterbodies (0.87) and 0-100 $\mathrm{m}(0.84)$ distance from road indicating the highest correlation with landslide occurrence. Further, the slope gradient directly relates to landslides occurrence as steeper slopes tend to be more unstable than flatter terrains. It was interpreted from the data that slope gradient classes, namely; steep $\left(35^{\circ}-45^{\circ}\right)$ and very steep $\left(>45^{\circ}\right)$, had the highest CF values and were more prone to landslides, whereas no landslides were reported for flat $\left(<15^{\circ}\right)$ slope gradient class. Similarly, it was observed that the probability of landslides was moderate at lower elevations $(400 \mathrm{~m}-1000 \mathrm{~m})$ due to modest terrain characteristics. The highest probability of landslides was observed at high elevations $(2000 \mathrm{~m}-$ $2500 \mathrm{~m})$. At very high elevations $(2500 \mathrm{~m}-3500 \mathrm{~m})$, the probability of landslides again decreases. This might be attributed to lesser reporting of landslides due to rugged terrain at areas with higher elevations. Regarding the geological aspects, the Middle Siwalik Group was found to have the highest CF values (0.74). This group predominantly consists of medium to coarse grained sandstone and red clay alternation, soft pebble with subordinate claystone and a locally thick prism of the conglomerate which might be attributed to its higher landslide susceptibility. During the analysis of soil classes, the highest CF was obtained for the lesser Himalayan soils of fluvial valleys (0.75), followed by Siwalik soils of side and reposed slopes (0.62). Both these soil types are described as loamy to loamy-skeletal soils, facilitating moderate to severe erosion.

The analysis of the Shanon Entropy model indicated that the highest $\mathrm{W}_{\mathrm{ij}}$ values were obtained for drainage density, TWI, NDVI and distance from road factors and highest $\mathrm{P}_{\mathrm{ij}}$ values were attributed to very high drainage density (0.58), very high TWI (0.42), NDVI waterbodies (0.57) and 0-100 m distance from roads (0.35). Hence these factors had the highest influence on landslide occurrence. Along with these, the areas with steep $\left(35^{\circ}-45^{\circ}\right)$ and very steep $\left(>45^{\circ}\right)$ slopes and moderately high elevation class was found to have the highest $\mathrm{P}_{\mathrm{ij}}$ values and had a moderate influence on landslides occurrence. The geology map analysis again confirms that the Middle Siwalik Group, with the highest $\mathrm{P}_{\mathrm{ij}}$ value (0.15), was highly prone to landslides, followed by the Dharmasala Group. Similarly, soil classes analysis confirms that the fluvial valley soils of lesser Himalayas with the highest $\mathrm{P}_{\mathrm{ij}}$ value $(0.70)$ were highly prone to landslides because of their shallow depth and excessive drainage characteristics. All other landslide causative factors such as aspect, curvature, lineament density etc. and their classes with the highest FR, CF and SE values had low to moderate influence on landslides occurrence.

\subsection{Accuracy Assessment and Validation of Models}

In this study, the $\mathrm{LSM}_{\mathrm{N}}$ and $\mathrm{LSM}_{\mathrm{R}}$ maps prepared using FR, CF and SE models were evaluated for accuracy of prediction and validation using ROC curves and AUC technique. These are well known techniques to determine the quality of a statistical model by plotting the fraction of true positives values out of total positives values and false positives values out of total negatives values by determining Sensitivity and Specificity (Devkota et al., 2013; Nohani et al., 2019). Each model's prediction rate curve was plotted using training data set of 1199 landslides (70\%), and the validation rate curve of each model was plotted using a validation data set of 524 landslides (30\%). The relative ROC curves of the three models are shown in Figure 6. Based on the ROC results and AUC evaluation, all three models offer the satisfactory prediction and validation accuracy. However, the Shanon Entropy model was found to have the most accurate prediction and validation for landslide susceptibility mapping of $\mathrm{LSM}_{\mathrm{N}}$ and $\mathrm{LSM}_{\mathrm{R}}$ maps.

\section{Discussion}

The process of generation of LSM maps is complex and requires multistep in depth analysis. This study analyses three main issues: (a) the mapping of landslide susceptibility of Mandi district based on relevant landslide causative factors (b) the comparison of three statistical models, namely Frequency Ratio (FR), 
Certainty Factor (CF) and Shanon Entropy (SE) for their accuracies in predicting landslides and (c) the assessment of landslide susceptibility change due to road construction in Mandi district.

An appropriate selection of landslide causative factors requires extensive knowledge of geographical and topographical aspects of the study area and triggering mechanisms associated with them (Guzzetti et al., 1999; Costanzo et al., 2012). Generally, the optimal approach is manual selection based on expert opinion, but there are no universal guidelines for identification and selection of landslide causative factors (Dou et al., 2015). Based on this criterion, eleven landslide causative factors were identified, all of whom had a strong association with landslide occurrence. Further, the interdependence of these factors was investigated using a multicollinearity test, which indicated that the selected factors were independent and credible. Analysis of the three statistical models results revealed that drainage density, distance from the road, TWI and NDVI were the most influential factors for landslide occurrence. At the same time, the slope curvature and aspect were the least influential factors on landslide occurrence. The rest of the parameters, such as elevation, lineament density, geology and soil, had a moderate impact on landslide occurrence. A high density of drainage networks and steeper slopes, and sedimentary rocks like medium to coarse grained sandstone and conglomerate can be attributed as principle factors of landslide occurrence in the study area. These factors, especially when combined with excessively drained soils, high lineament density and improper road construction activities, tend to increase the study area's landslide susceptibility. Further, the NDVI map analysis suggested that the areas near waterbodies and the areas interfered with by human settlements, road construction or any other infrastructure development activities tend to be more prone to landslides. On the contrary, regions having very high elevations, a higher percentage of vegetation and flatter slope gradients have minimum susceptibility to landslides. These results conform with the findings of similar research reports. (Dou et al., 2015; Hong and Bui, 2015; Roy, 2019).

Statistical modelling is an essential component in determining the landslide susceptibility of an area. The accuracy of statistical models is primarily dependent upon the data quality and model structure. In this study, three statistical models, namely: FR, CF and SE, were used to determine the Mandi district's landslide susceptibility. The validation of these models was done using ROC curves and the AUC technique, assuming that landslides were dependent only on the given spatial parameters with rainfall as the common triggering factor. The results indicate that all three models have satisfactory values for prediction and accuracy. Still, the relative contribution of the landslide causative factors varied with the models, as shown in Figure 6. The highest accuracy of prediction and validation was demonstrated by Shanon Entropy (83-86\%). The SE model is an entropy based data driven model which directly stores information of variables and correlates with the probability of landslide occurrence. This might be the reason for its higher accuracy in comparison to the other two models. The SE model indicated that drainage density and distance from roads as the two major contributing factors towards landslide susceptibility. The SE model also suggested a strong correlation between higher slope gradient and TWI and landslide occurrence. Some other factors like NDVI, soil, geology and elevation also indicated significant contribution. The geology Dharmasala Group, Dagshai and Kasauli Formations combined with soils of fluvial valleys at moderate to high elevations showed the highest correlation with landslide occurrence. FR model being on the observation model had (75-79\%) accuracy of prediction and validation. As a rule-based model, the CF model had a relatively good accuracy of predicting and validating (75-82\%). These models also suggested drainage density and road construction as two fundamental factors with maximum impact on landslide susceptibility in the study area. The comparison of these models was found to be in accordance with recent studies of landslide susceptibility analysis. (Devkota et al., 2013; Lee and Pradhan, 2007; Nohani et.al, 2019; Wang et al., 2015).

In this study, the $\mathrm{LSM}_{\mathrm{N}}$ and $\mathrm{LSM}_{\mathrm{R}}$ maps were prepared using FR, CF and SE models. The results of all the models indicated that the road construction activities in the Mandi district appear to be a primary factor responsible for an increase in landslide susceptibility of the study area. For comparison, ten common landslide causative factors were considered for preparing two susceptibility maps. The additional factor of the distance from the road was only considered for the $\mathrm{LSM}_{R}$ map. These susceptibility maps are further classified into five zones of susceptibility: very low, low, moderate, high and very high susceptibility. The analysis of change in susceptibility was done by comparing each class's percentages in both $\mathrm{LSM}_{\mathrm{N}}$ and $\mathrm{LSM}_{\mathrm{R}}$ maps, as shown 
in Table 4. The analysis of $\mathrm{LSM}_{N}$ and $\mathrm{LSM}_{\mathrm{R}}$ maps of FR model indicates that the percentage of area in high susceptibility zone increases from $22.9 \%$ in $\mathrm{LSM}_{\mathrm{N}}$ map to $24.5 \%$ in $\mathrm{LSM}_{\mathrm{R}}$ map and the percentage of area in very high susceptibility zone increases from $13.2 \%$ in $\mathrm{LSM}_{\mathrm{N}}$ map to $15.8 \%$ in $\mathrm{LSM}_{\mathrm{R}}$ map.

Similarly, for the CF model, the high susceptibility zone area increases from $23 \%$ in the $\mathrm{LSM}_{\mathrm{N}}$ map to $24 \%$ in the $\mathrm{LSM}_{\mathrm{R}}$ map. The area is very high susceptibility zone increases from $7 \%$ in $\mathrm{LSM}_{\mathrm{N}}$ map to $8 \%$ in $\mathrm{LSM}_{\mathrm{R}}$ map. Likewise, in the SE model having the highest prediction accuracy, it was observed that the percentage of area in high susceptibility zone increases from $19.3 \%$ in $\mathrm{LSM}_{\mathrm{N}}$ map to $21.6 \%$ in $\mathrm{LSM}_{\mathrm{R}}$ map, and the percentage of area in very high susceptibility zone increases from $10.8 \%$ in $\mathrm{LSM}_{\mathrm{N}}$ map to $12.5 \%$ in $\mathrm{LSM}_{R}$ map. It can be observed from the $\mathrm{LSM}_{R}$ maps in Figure 5. that the areas in the vicinity of the road, particularly in classes $(0-100 \mathrm{~m})$ and $(100-200 \mathrm{~m})$, witnessed an increase in landslide susceptibility. This can be attributed to the fact that the cutting and tempering of natural bed slope for road construction increases the risk of slope failure in that area. Additionally, road construction may change or block the natural drainage networks operating in mountainous terrains. This might further increase the probability of landslide occurrence in that area.

\section{Conclusions}

Landslide susceptibility mapping is crucial, keeping in mind the futuristic development plans in mountainous regions. In the present study, 1723 landslides and 11 causative factors with high correlation to landslide occurrences were used for landslide susceptibility analysis. The landslide susceptibility maps were prepared using frequency ratio (FR), certainty factor (CF) and Shanon Entropy (SE) models and were further classified into five classes i.e. low, moderate, high, and very high susceptibility zones. The accuracy of these models were assessed using Receiver Operating Characteristics (ROC) method and area under the curve (AUC) technique. The FR model's prediction and validation accuracy lie between (75-79\%) and for the CF model lies between (75-82\%). The highest accuracy of prediction and validation was observed for the SE model (83-86\%), and hence SE model is recommended for similar studies in the future. The analysis of three models indicate that very high drainage density and TWI, NDVI waterbodies and a distance of $(0-100 \mathrm{~m})$ from roads are the four most predominant factors influencing the landslide susceptibility in mountainous region. Further analysis of $\mathrm{LSM}_{\mathrm{N}}$ and $\mathrm{LSM}_{\mathrm{R}}$ maps implied a $2.67-4.17 \%$ increase in the areas with high and very high susceptibilities due to road construction in the study area. Hence, the road construction in hilly region increases the landslide susceptibility so a better planning and construction management is required to mitigate the impact of road construction on landslide susceptibility.

\section{References}

Ahmad M, Umrao RK, Ansari MK, Singh R, Singh TN. 2013. Assessment of Rockfall Hazard along the Road Cut Slopes of State Highway-72, Maharashtra, India. Geomaterials. 03(01):15-23.

Akgun A, Dag S, Bulut, F. 2008. Landslide susceptibility mapping for a landslide-prone area (Findikli, NE of Turkey) by likelihood-frequency ratio and weighted linear combination models. Environ. Geol., 54:1127-1143.

Ayalew L, Yamagishi H. 2005. The application of GIS-based logistic regression for landslide susceptibility mapping in the Kakuda-Yahiko Mountains, Central Japan. Geomorphology 65:15-31.

Balsubramani K and Kumaraswamy K. 2013. Application of geospatial technology and information value technique in landslide hazard zonation mapping: A case study of Giri Valley, Himachal Pradesh. Disaster, 6:38-47.

Banshtu RS, Prakash C. 2014. Application of Remote Sensing and GIS Techniques in Landslide Hazard Zonation of Hilly Terrain. Landslide Science for a Safer Geoenvironment. Springer. https://doi.org/10.1007/9783-319-05050-8_49. 
Bednarik M, Magulová B, Matys M, Marschalko M. 2010. Landslide susceptibility assessment of the Kral'ovany Liptovský Mikuláš railway case study. Phys. Chem. Earth Parts A/B/C 2010, 35:162-171.

Beven, K.J.; Kirkby, MJ 1979. A physically based, variable contributing area model of basin hydrology. Hydrological Science Bulletin. 24 (1):43-69. doi:10.1080/0262666r909491834 .

Bonham-Carter, GF. 2014. Geographic Information Systems for Geoscientists: Modelling with GIS vol. 13; Elsevier: Amsterdam, The Netherlands.

Brabb EE. 1984. Innovative approaches to landslide hazard mapping. In: Proc. 4th Int. Symp. Landslides, Toronto. 1:307-324.

Carrara A, Cardinali M, Detti R, Guzzetti F, Pasqui V, Reichenbach P. 1991. GIS techniques and statistical models in evaluating landslide hazard. Earth Surf. Process. Landf. 16 (5):427-445. http://dx.doi.org/10.1002/esp.3290160505.

Carrara A, Sorriso-Valvo M, Reali C. 1982. Analysis of landslide form and incidence by statistical techniques, Southern Italy. Catena 9 (1-2):35-62. http://dx.doi.org/10. 1016/s0341-8162(82)80004-0.

Ceballos-Silva, A. and Lopez-Blanco, J. 2003. Delineation of Suitable Areas for Crops Using a Multi-Criteria Evaluation Approach and Land Use/Cover Mapping: A Case Study in Central Mexico. Agricultural Systems, 77:117-136. https://doi.org/10.1016/S0308-521X(02)00103-8.

Chang K. and Liu J. 2004. Landslide features interpreted by neural network method using a high resolution satellite image and digital topographical data. Proceedings of 20th ISPRS Congress, (ISPRSC' 04), Istambul.

Choubey, VM, Mukherjee PK, Bajwa BS and Walia V. 2007. Geological and tectonic influence on the water-soil-radon relationship in Mandi-Manali area, Himachal Himalaya. Environ. Geol., 55:1163-1171. doi: 10.1007/s00254-006-0553-1.

Chung C, Fabbri JF, Van Westen AG. 1995. Multivariate regression analysis for landslide hazard zonation. In: Carrara, A., Guzzetti, F. (Eds.), Geographical Information Systems in Assessing Natural Hazards. Kluwer Academic Publisher, Dordrecht, The Netherlands:107-142.

Costanzo D, Rotigliano E, Irigaray C, Jiménez-Perálvarez JD, Chacón J. 2012. Factors selection in landslide susceptibility modelling on a large scale following the gis matrix method: application to the river Beiro basin (Spain). Nat Hazards Earth Syst Sci. doi: 10.5194/nhess-12-327-2012.

Crozier MJ, Glade T. 2005. Landslide Hazard and Risk: Issues, Concepts and Approach. In:Glade T, Anderson M, Crozier MJ (eds.), Landslide Hazard and Risk. Wiley, Chichester:1-40.

Crozier MJ. 1989. Landslides: causes, consequences \& environment. Croom Helm Pub, London.

Demir G, Aytekin M \& Akgun A. 2014 Landslide susceptibility mapping by frequency ratio and logistic regression methods: An example from Niksar-Resadiye (Tokat, Turkey). Arabian Journal of Geosciences. https://doi.org/10.1007/s12517-014-1332-z.

Devkota KC, Regmi AD, Pourghasemi HR, Yoshida K, Pradhan B, Ryu IC, Dhital MR, Althuwaynee OF. 2013. Landslide susceptibility mapping using certainty factor, index of entropy and logistic regression models in GIS and their comparison at Mugling-Narayanghat road section in Nepal Himalaya. Nat Hazards. 65(1):135-165.

Dietrich EW, Reiss R, Hsu, ML, Montgomery DR. 1995. A process-based model for colluvial soil depth and shallow landslides using digital elevation data. Hydrological Process 9:383-400.

Dou J, Bui DT, Yunus AP, Jia K, Song X, Revhaug I, Xia H, Zhu Z. 2015. Optimisation of causative factors for landslide susceptibility evaluation using remote sensing and GIS data in parts of Niigata, Japan.

http://dx.doi.org/10.1371/journal.pone.0133262. 
Dou J, Oguchi T, Hayakawa YS, Uchiyama S, Saito H, Paudel U. 2014. Susceptibility Mapping Using a Certainty Factor Model and Its Validation in the Chuetsu Area, Central Japan. Landslide Sci a Safer Geoenvironment. 2:483-489. doi: 10.1007/978-3-319-05050-8_6517.

Erener A, Düzgün HSB. 2012. Landslide susceptibility assessment: what are the effects of mapping unit and mapping method? Environ. Earth Sci. 66 (3):859-877. https://doi.org/10.1016/S0341- 8162(02)00170-4.

Fell R. 1993. Landslide risk assessment and acceptable risk. Can. Geotech. J., 31:261-272.

Frangov G, Petkova V, Stoyanov V, Kadiyski M, Kostov V, Papaliangas T.2017. Landslide Risk Assessment and Mitigation Along a Road in Sw Bulgaria. Fresenius Environment Bulletin, 26(1):244-253.

Glade T. 2003. Landslide occurrence as a response to land-use change: a review of evidence from New Zealand. Catena 51:297-314.

https://doi.org/10.1016/S0341- 8162(02)00170-4.

Gomez H, Bradshow R, and Mather P. 2000. Monitoring the Distribution of Shallow Landslide Prone Areas Using Remote Sensing, DTM and GIS - a Case Study from the Tropical Andes of Venezuela. In: Remote Sensing in 21st Century: Economic and Environmental Applications, Casanova, E. (Ed.), Balkema, Rotterndam:395-401.

Guzzetti F, Carrara A, Cardinali M, Reichenbach P. 1999. Landslide hazard evaluation: a review of current techniques and their application in a multi-scale study, Central Italy. Geomorphology:181- 216.

doi: 10.1016/S0169-555x (99)00078-1.

Guzzetti F. 2005. Landslide Hazard and Risk Assessment. In: PhD Thesis. Mathematics- Scientific Faculty. The University of Bonn, Bonn, Germany.

Guzzetti F, Reichenbach P, Ardizzone F, Cardinali M, Galli M. 2006b. Estimating the quality of landslide susceptibility models. Geomorphology 81:166-184. http:// dx.doi.org/10.1016/j.

geomorph.2006.04.007.

Henriques CS and Zezere JL. 2009. Propagation of landslide inventory errors on data driven landslide susceptibility models. In: Geophysical Research Abstracts, EGU General Assembly.

Hong H, Xu C, Bui DT. 2015. Landslide Susceptibility Assessment at the Xiushui Area (China) Using Frequency Ratio Model. Procedia Earth Planet Sci. 15:513-517.

Huabin, Wang \& Gangjun, Liu \& Weiya, Xu, Wang, Gonghui. 2005. GIS-based landslide hazard assessment: An overview. Progress in Physical Geography:548-567.

Hutchinson J N. 1988. General report: morphological and geotechnical parameters of landslides in relation to geology and hydrogeology. In: Proc 5th International Symposium on Landslides, Lausanne, 10-15 July 1988V1:3-35.

Ilia I, Koumantakis I, Rozos D, Koukis G, Tsangaratos P. 2015. A geographical information system (GIS) based probabilistic certainty factor approach in assessing landslide susceptibility: The case study of Kimi, Euboea, Greece. In Engineering geology for society and territory Berlin: Springer Vol. 2:1199-1204.

Godt JW, Baum RL, and Lu N. 2009. Landsliding in partially saturated materials, Geophysical Research Letters, vol. 36:2.

Jaiswal P, Van Westen CJ, Jetten V. 2009. Quantitative landslide risk assessment along the transportation lines in southern India. In: ITC, Enshede, Netherlands:27.

Jebur MN, Pradhan B, Tehrany MS. 2014b. Detection of vertical slope movement in the highly vegetated tropical area of Gunung pass landslide, Malaysia, using L-band InSAR technique. Geosci J 18:61-68. 
Kanungo DP, Sarkar S, Sharma S. 2011. Combining neural network with fuzzy, certainty factor and likelihood ratio concepts for spatial prediction of landslides. Nat Hazards 59:1491-1512.

Kanungo D \& Arora, Manoj \& Sarkar, Shantanu \& Gupta RP. 2009. Landslide Susceptibility Zonation (LSZ) Mapping - A Review. Journal of South Asia Disaster Studies:81-105.

Karim S, Jalileddin S, Ali MT. 2011. Zoning landslide by use of frequency ratio method (case study: Deylaman Region). Middle-East Journal of Scientific Research, 9(5):578-583.

Lee EM, Jones DKC 2004. Landslide Risk Assessment. Thomas Telford, London:454

Lee S, Pradhan B. 2007. Landslide hazard mapping at Selangor, Malaysia using frequency ratio and logistic regression models. Landslides. 4(1):33-41.

Lee S, Talib JA. 2005. Probabilistic landslide susceptibility and factor effect analysis. Environ Geol; 47:982990. doi: $10.100 \% / s 00254-005-1228$.

Liu M, Chen X, Yang S. 2014. Collapse landslide and mudslide hazard zonation. In: Landslide Science for a safer geoenvironment. Springer International Publishing:457-462.

Mantovani F, Soeters R, Van Westen CJ. 1996. Remote sensing techniques for landslide studies and hazard zonation in Europe. Geomorphology 15(3-4):213-25.

Nohani E, Moharrami M, Sharafi S. Khosravi K, Pradhan B, Pham B, Lee S, Melesse A. 2019. Landslide Susceptibility Mapping Using Different GIS-Based Bivariate Models. Water:11. doi: 10.3390/w11071402.

Mzuku M, Khosla R, Reich R, Inman D, Smith F, MacDonald F .2005. Spatial variability of measured soil properties across site-specific management zones, Soil Sci. Soci. Am. J., 69(5):1572.

doi:10.2136/sssaj2005.0062.

Nagarajan R, Mukherjee A, Roy A, Khire M V. 1998. Temporal remote sensing data and GIS application in landslide hazard zonation of part of the Western ghat, India. Int J Remote Sens. 19(4):573-585.

Nayak J. 2010. Landslide risk assessment along a major road corridor based on historical landslide inventory and traffic analysis. Geo-Information Science:104.

https://doi.org/10.4049/jimmunol.1301497.

Pham BT, Bui DT, Prakash I, Dholakia M. 2017. Hybrid integration of Multilayer Perceptron Neural Networks and machine learning ensembles for landslide susceptibility assessment at Himalayan area (India) using GIS. Catena: 149:52-63.

Pourghasemi HR, Mohammady M, Pradhan B. 2012e. Landslide susceptibility mapping using the index of entropy and conditional probability models in GIS: Safarood Basin, Iran. Catena 97:71-84. doi: 10.1016/j.catena.2012.05.005.

Pradhan B, Abokharima MH, Jebur MN, Tehrany MS. 2014. Land subsidence susceptibility mapping at Kinta Valley (Malaysia) using the evidential belief function model in GIS. Nat Hazards 73:1019-1042.

Pradhan SP, Vishal V, Singh TN. 2018. Finite element modelling of landslide prone slopes around Rudraprayag and Agastyamuni in Uttarakhand Himalayan terrain. Nat Hazards.

https://doi.org/10.1007/s11069-018-3381-1.

Pradhan B, Lee S. 2010. Landslide susceptibility assessment and factor effect analysis: Back propagation artificial neural networks and their comparison with frequency ratio and bivariate logistic regression. Environmental Modelling \& Software, 25:747-759. 
Baum RL, Godt JW, Savage WZ.2010. Estimating the timing and location of shallow rainfall-induced landslides using a model for transient, unsaturated infiltration, Journal of Geophysical Research, vol. 115, no. F3.

Ramakrishnan D, Singh TN, Verma AK, Gulati A, Tiwari KC. 2013. Soft computing and GIS for landslide susceptibility assessment in Tawaghat area, Kumaon Himalaya, India. Nat Hazards 65(1):315- 330 .

https://doi.org/10.1007/s11069-012-0365-4.

Reichenbach P, Rossi M, Malamud BD, Mihir M, Guzzetti F. 2018. A review of statistically-based landslide susceptibility models. Earth-Science Reviews, 180(March):60-91.

https://doi.org/10.1016/j.earscirev.2018.03.001.

Remondo J, González A, De Terán JRD, Cendrero A, Fabbri A, Chung CJF. 2003. Validation of landslide susceptibility maps; examples and applications from a case study in Northern Spain. Nat. Hazards 30:437449. http://dx.doi.org/10.1007/s00267-014-0357-0.

Rengers N, Soeters R, Van Westen CJ. 1992. Remote sensing and GIS applied to mountain hazard mapping. Episode, 15:36-45.

Rossi M, Guzzetti F, Reichenbach P, Mondini AC, Peruccacci S. 2010. Optimal landslide susceptibility zonation based on multiple forecasts. Geomorphology 114 (3):129-142.

http://dx.doi.org/10.1016/j.geomorph.2009.06.020.

Roy J, Saha S, Arabameri A, Blaschke T, Bui DT. 2019. A Novel Ensemble Approach for Landslide Susceptibility Mapping (LSM) in Darjeeling and. Remote Sens. 11(23):2886.

Saha AK, Gupta RP, Sarkar I, Arora MK, Csaplovics E. 2005. An approach for GIS-based statistical landslide susceptibility zonation - with a case study in the Himalayas. Landslides 2 (1):61-69.

http://dx.doi.org/10.1007/s10346-004-0039-8.

Soeters R, Rengers N, Van Westen CJ. 1991. Remote sensing and GIS as applied to mountain hazard analysis and environmental monitoring. In Proceedings of 8th Thematic Conference on Geological Remote Sensing, Denver, Colorado, 29 April-2 May.

Tuan T, Dan N. 2012. Landslide susceptibility mapping and zoning in the Son La hydropower catchment area using the analytical hierarchy process. J. Sci. Earth.

Van Westen CJ. 2000. The modelling of landslide hazards using GIS. Survey Geophysics 21:241-255.

Varnes. D.J (1984) Landslide Hazard Zonation: A Review of Principles and Practice. Paris: United Nations International.

Wang Q, Li W, Chen W, Bai H. 2015. GIS-based assessment of landslide susceptibility using certainty factor and index of entropy models for the Qianyang county of Baoji city, China. J Earth Syst Sci. 124(7):1399-1415.

\section{Hosted file}

Figures.pdf available at https://authorea.com/users/403733/articles/522406-evaluating-theimpact-of-road-construction-on-landslide-susceptibility-a-case-study-of-mandi-districthimachal-pradesh-india

\section{Hosted file}

Tables.pdf available at https://authorea.com/users/403733/articles/522406-evaluating-theimpact-of-road-construction-on-landslide-susceptibility-a-case-study-of-mandi-districthimachal-pradesh-india 